\title{
EL ROL DE LOS INTELECTUALES EN LA SEGUNDA POSGUERRA, A TRAVÉS DE LAS PERSPECTIVAS DE RAYMOND ARON, JEAN-PAUL SARTRE Y HERBERT MARCUSE
}

\author{
Andrea Iglesias \\ Universidad de Buenos Aires, Argentina
}

\begin{abstract}
Resumen.- El presente artículo se propone analizar las tensiones en torno al rol de los intelectuales a partir de las obras de Raymond Aron, Jean Paul Sartre y Herbert Marcuse en el contexto de la denominada Guerra Fría. Dado el objetivo del presente trabajo, que se enmarca en la perspectiva de la historia de los intelectuales, hemos seleccionado a estos autores por considerarlos relevantes en el pensamiento filosófico y político de este período, así como también porque sus reflexiones expresan algunas de las críticas al rol ejercido por los intelectuales europeos durante la segunda posguerra (particularmente en el contexto francés y alemán). Para este fin, hemos elegido las siguientes obras: El opio de los intelectuales (Aron, 1955), El fin de la utopía (Marcuse, 1968) y Alrededor del '68 (Sartre, 1972), ya que consideramos condensan sus reflexiones a cerca del propio accionar en tanto intelectualesmilitantes, atravesados por la experiencia de la Segunda Guerra Mundial. A modo de síntesis, observamos que mientras R. Aron posee una perspectiva reformista sobre la sociedad de posguerra, signada por su propio desencanto hacia el proyecto soviético, J. P. Sartre y $\mathrm{H}$. Marcuse, por su parte, encuentran en esta coyuntura la oportunidad histórica para generar una transformación estructural, en la que los intelectuales tendrían una participación central en la concientización del proletariado europeo.
\end{abstract}

Palabras cl ave.- rol de los intelectuales; guerra fría; historia de los intelectuales; Aron; Marcuse; Sartre

Abstract.- The aim of this article is to analyze the tensions concerning the role of the intellectuals, based on the works of Raymond Aron, Jean Paul Sartre and Herbert Marcuse, in the context of the "Cold War". Given the goal of this work, which is placed within the perspective of "intellectual history", we have selected these authors by considering them to be relevant in the philosophical and political thought of this period, as well as also because their reflections express some of the critiques to the role played by the intellectual Europeans during the second postwar period (particularly in the French and German context). To this end, we have chosen the following works: The opium of the intellectuals (Aron, 1955), The End of Utopia (Marcuse, 1968) and Autour de 68, Situations VIII (Sartre, 1972), since we consider these works gather their reflections about their own actions about both intellectual and activist roles, conditioned by the experience of the Second World war. Summarizing our findings, we observe that, while R. Aron possesses a reformist perspective upon the society of postwar period, strongly marked by his own disenchantment towards the Soviet project, J. P. Sartre and $\mathrm{H}$. Marcuse find in this juncture the historical opportunity to generate a structural transformation, in which the intellectuals would have a central participation in the awareness of the European proletariat.

Key words.- Intellectual roles; cold war; intellectual History; Aron; Marcuse; Sartre 


\section{Introducción}

En el presente trabajo nos proponemos analizar las tensiones existentes en torno al rol de los intelectuales en el contexto de la segunda post guerra y la llamada Guerra Fría. Para ello hemos seleccionado a tres intelectuales, Raymond Aron, Jean Paul Sartre y Herbert Marcuse, por considerarlos grandes exponentes del pensamiento filosófico y político del siglo XX. Sus reflexiones, situadas particularmente en el contexto francés y alemán, nos permitirán poner en tensión diferentes posturas durante la post guerra acerca de la "misión" de los intelectuales y su lugar en tanto que actores sociales.

A este respecto, es preciso aclarar que nuestro trabajo se enmarca en la perspectiva de la historia de los intelectuales, y es desde ella que intentaremos desandar las problemáticas que trabajaron estos autores.

A los fines de la comparación, hemos seleccionado tres de sus obras: El opio de los intelectuales (R. Aron, 1955), El final de la utopía (H. Marcuse, 1968) y Alrededor del 68. Situación ocho (J. P. Sartre, 1972). Así mismo, quisiéramos aclarar que si bien sería deseable incorporar aportes de otras obras, su análisis excede los objetivos de este trabajo. No obstante incorporaremos algunas reflexiones cuando sean necesarias.

En las líneas siguientes, intentaremos dar cuenta de la perspectiva de estos intelectuales, realizando un análisis comparativo a través de cinco ejes, siempre teniendo presente la importancia de historizar su contexto de producción.

Por último, quisiéramos hacer explicita la inquietud que motivó la producción de este trabajo y que nos llevó a ahondar sobre esta problemática. Creemos que son los problemas o preguntas que se nos presentan a lo largo de nuestro período de formación, los que orientan finalmente la selección de fuentes que deseamos analizar luego. En nuestro caso, fue y sigue siendo la incansable pregunta sobre cuál es el rol que nos es encomendado jugar (y cuál deseamos jugar) en la sociedad en que vivimos, nos formamos y producimos como intelectuales, la que ha guiado, en última instancia, el desarrollo de este trabajo.

\section{Nuestro enfoque}

Realizaremos una breve referencia a nuestro enfoque de trabajo. Contextualizar las obras en el período histórico en que fueron producidas es de vital importancia. Sin embargo, desde la historia de los intelectuales, es necesario, además, agregar otros elementos que permitan ver la intertextualidad, las tensiones entre líneas, la significación de la obra en el marco global de producción del autor, etc. Con ese objetivo, a continuación citaremos algunos trabajos de distintos autores que nos remiten a este tipo de análisis.

En términos de Carlos Altamirano (2005), la historia de los intelectuales, al privilegiar los "hechos del discurso", nos permite un desciframiento de la 
historia irremplazable, que no sólo remite los escritos al "campo de la acción" (a su contexto), sino que además trabaja sobre la "lectura interna" y la "interpretación" de éstos. Paul Ricoeur nos acerca aún más a esta idea de que "[...] la lectura es este acto concreto en el cual se consuma el destino del texto. En el corazón mismo de la lectura se oponen y se concilian indefinidamente la explicación y la interpretación" (2006: 147). El "re-decir" y el acto de "apropiación" del texto que hacemos al interpretarlo, libera a la escritura del lugar del habla y la coloca en el texto, donde el lector asume su rol como interlocutor. Desde Roger Chartier, la historia de los intelectuales intenta "articular" la producción intelectual en sí, en relación con "otras producciones culturales contemporáneas" por los "distintos campos de discurso" que rodean a la obra del intelectual. Finalmente, Dominick La Capra, manifiesta que en "la comprensión histórica", la cuestión de la "textualidad" ocupa un lugar central. No debemos olvidar así, que a los "aspectos documentarios" de un texto, se le agrega su "ser-obra" que excede esa dimensión fáctica del escrito, que es indispensable para abordar la relación de los textos con sus contextos, y a su vez con el "conjunto de contextos interactuantes" que se encuentran en tensión al interior del discurso.

Desde este encuadre, nuestra intención será trabajar con las obras en tanto interlocutores, explicando e interpretando las tensiones que podamos observar entre los intelectuales y al interior mismo de su producción. Este abordaje, lejos de constituir un modelo que nos encorseta, nos permite pensar a los intelectuales no sólo como autores, sino además como actores político-sociales dentro de su contexto, de forma tal que sus obras cobren vida y mayor significado.

\section{Contextualización}

En primer lugar, contextualizaremos históricamente la construcción del discurso de nuestros intelectuales; en segundo lugar, situaremos la trayectoria de los intelectuales; y, en tercer lugar, contextualizaremos las obras dentro de la producción general de éstos.

El período de la segunda post guerra está determinado por el enfrentamiento de las dos superpotencias que surgen al finalizar la contienda: Estados Unidos y la Unión Soviética. Según Eric J. Hobsbawm (1995), ambos bloques protagonizarán la denominada "Guerra Fría", signada por la sensación de la población mundial de que el ataque entre ambos sería inminente: "[...] mientras a Estados Unidos le preocupaba el peligro de una hipotética supremacía mundial de la URSS en el futuro, a Moscú le preocupaba la hegemonía real de los Estados Unidos en el presente sobre todas las partes del mundo no ocupadas por el ejército rojo" (1995: 238). Pese a ello, se desarrollará una "paz fría", sin enfrentamientos bélicos directos entre ambas potencias, que sin embargo sí llevó a enfrentamientos indirectos por la intervención de ambas, en conflictos de otros países.

Para ambos bloques y para los países europeos, la recuperación tras la Segunda Guerra Mundial era prioritaria, pero no fue hasta los 60' que comprendieron la prosperidad alcanzada, con la penetración de la "revolución tecnológica" en la "conciencia del consumidor", con los llamados "siete grandes del capitalismo" en el centro de las economías más prósperas (2005: 260). 
Este enfrentamiento entre las potencias, no sólo estaba dado en el campo bélico, también alcanzaba y se manifestaba en el campo de los intelectuales. Así, desde ambos bloques se produjeron acusaciones y se recalcaron los errores del oponente. En este contexto, se situaron nuestros intelectuales. Observaremos, entonces, en sus obras estos enfrentamientos.

Continuemos ahora situando muy brevemente la trayectoria de los intelectuales que analizaremos ${ }^{1}$. En primer término, Raymond Aron (1905-1983), de familia judía, filósofo y sociólogo francés, doctorado en Filosofía de la Historia, fue testigo del antisemitismo previo al ascenso de Hitler. Se declaraba abiertamente socialista en su juventud, para convertirse luego en reformista, ferviente crítico del comunismo. Luego de su exilio en Londres durante la ocupación nazi, regresará a Francia finalizada la guerra, para escribir en Le Figaro y más tarde en L'Express. Se manifestó en contra del régimen soviético, acercándose a una postura pronorteamericana. Desde esta perspectiva, fue un referente central del Congreso por la Libertad de la Cultura (Berlín, 1950), que desemboca en escándalo por el financiamiento encubierto del la CIA. Ingresó como profesor de la Facultad de Filosofía y Letras de la Soborna en París desde 1955 y en 1970 en el College de France. Durante los sucesos del Mayo Francés, participó activamente de la reacción conservadora de la universidad. Estos acontecimientos lo enemistaron fuertemente con Sartre, quien había sido su compañero de promoción de la Escuela Normal, y frente al cual siempre había tenido menor popularidad para la opinión pública francesa.

Prosigamos con Jean-Paul Sartre (1905-1980). Este filósofo y escritor francés, Doctor en Filosofía, tras servir en la Ejército Francés, fue capturado por tropas alemanas y trasladado a distintos campos de concentración; una vez liberado, participó activamente de la resistencia francesa, y en 1945 funda Les Temps Modernes, una revista de análisis literario y político. Se convierte luego en compañero de ruta del PC francés (previa militancia en el partido), mientras desempeñaba un papel importante en la lucha contra el colonialismo francés (coincidiendo con la guerra de liberación de Argelia). Fue crítico del stalinismo y se opuso a la Guerra de Vietnam, participando activamente del denominado "Tribunal Russell", cuyo propósito era exponer los crímenes de guerra de EE.UU. Ya hacia el final de su vida, adhiere a la revuelta estudiantil del Mayo del 68', constituyéndose en un referente de este movimiento.

Finalmente, Herbert Marcuse (1898-1979), nació en Berlín en el seno de una familia judía. Desarrolló una trayectoria intelectual comprometida como filósofo y sociólogo de la Escuela de Francfort. Habiendo servido como soldado en la Primera Guerra, participó de la revolución socialista en la Alemania anterior a la República de Weimar. Bajo el régimen nazi, no se le permitió terminar sus estudios por ser judío, por lo que en 1940 emigró a EE.UU. Luego de adquirir la nacionalidad norteamericana, impartió clases en las Universidades de Columbia y Harvard, entre otras. Desde EE.UU., produjo gran parte de su obra, y su análisis y críticas a la sociedad capitalista se hicieron eco en las

\footnotetext{
${ }^{1}$ Quisiéramos aclarar que a los fines del presente trabajo, y dada la extensión del mismo, nos excede realizar un análisis más extenso de la vida y obra de los intelectuales a tratar. Consideramos sin embargo, que dado que el objetivo de nuestro trabajo es comparativo, los datos suministrados al lector son de suficiente relevancia para comprender el contexto de producción al que deseamos referirnos.
} 
demandas estudiantiles en la Francia de los 60' así como en las reivindicaciones de los estudiantes alemanes de este período.

De los datos precedentes, podemos observar la activa participación de estos tres intelectuales para el período que estamos analizando. Han sido actores que vivenciaron de cerca la contienda mundial y la posterior escisión del mundo en dos bloques claramente delimitados durante la Guerra Fría. En sus escritos observaremos cómo se plasma el rol que han elegido jugar en medio de la batalla que se desarrolla en el campo intelectual entre las defensas al sistema norteamericano y soviético.

Por último, dentro de este apartado, debemos situar, para conocimiento del lector, el contexto de producción de cada obra que utilizaremos, puesto que allí también encontraremos datos que ayudan a entender su rol como intelectuales.

Comencemos con la obra elegida perteneciente a Sartre. Alrededor del 68. Situación ocho (1972), forma parte de la serie de ensayos que publicó durante su carrera. En él se compilan distintos tipos de textos producidos por el autor, como entrevistas, artículos periodísticos y declaraciones en distintos espacios culturales, varias conferencias y correspondencia con distintos actores políticos del período. Creemos que la riqueza de este ensayo radica en la posibilidad de contrastar la obra de su autor antes y después de determinados acontecimientos mundiales y de su propio país. Así, manifestó sus opiniones sobre los cuatro temas centrales en los que se encuentra dividido el libro: la Guerra de Vietnam, el conflicto árabe-israelí, los sucesos de Francia en Mayo de $1968 \mathrm{y}$, finalmente, un tema medular que recorre la obra pero al que además dedica un apartado especial: los intelectuales ${ }^{2}$. En este conjunto de ensayos, se muestra claramente a un intelectual preocupado por su tiempo, interviniendo en su contexto e interactuando con sus pares y también con actores políticos franceses. Sartre presentó aquí su postura acerca del rol que deben asumir los intelectuales, y particularmente luego del Mayo Francés, qué lugar ocuparon los estudiantes y los jóvenes en este contexto.

En cuanto a la obra seleccionada de Marcuse, El final de la utopía (1967), se trata de una serie de conferencias brindadas por él en la Universidad Libre de Berlín en 1967 (año en que fue publicada la obra), en un contexto de gran movilización y politización del movimiento estudiantil alemán. Luego de las obras centrales de Eros y Civilización (1953) y El hombre unidimensional (1964), donde Marcuse realizó una crítica a la sociedad moderna industrializada, El final de la utopía vino a condensar algunos de sus argumentos más interesantes en torno al rol de los intelectuales $y$, particularmente, de los estudiantes y los jóvenes alemanes. Esta obra agrupa las conferencias y las discusiones que se realizaron con diferentes profesionales de la universidad durante la estadía de Marcuse. Por esta razón, la obra goza de la voz de otros actores, que interpelaron a Marcuse, obligándolo a posicionarse frente a problemáticas del período. Entre ellas, en las conferencias se trabaja sobre la Guerra de Vietnam, el totalitarismo y el fascismo, los movimientos revolucionarios en el denominado "tercer mundo", colonialismo/imperialismo, conflictos del Oriente Próximo, la política de la

\footnotetext{
${ }^{2}$ Si bien analizaremos la obra en su totalidad, quisiéramos aclarar que nos centraremos en esta última parte, ya que es en ella donde encontramos los mayores aportes para nuestro trabajo.
} 
URSS, entre otros. También en esta obra, observamos como eje central el rol de los intelectuales, y el papel que desarrollaron los estudiantes y jóvenes universitarios.

Finalmente, la obra elegida de Aron, El opio de los intelectuales (1955) se constituyó (según las explicaciones del propio autor en su Prefacio), en el intento de explicar la actitud de los intelectuales comunistas franceses, en un contexto nacional donde degaullistas y socialistas pujaban por obtener el poder en el centro de la escena francesa. Aron se planteó en la obra discutir el marxismo de los intelectuales "comunizantes", a través de tres apartados donde reflexionó sobre: los "mitos políticos" (la revolución, la izquierda y el proletariado), la "idolatría de la historia" (el rol del partido, la utilidad y sentido de la historia, el fanatismo de ciertos intelectuales) $\mathrm{y}$, finalmente la parte que aquí nos convoca, lo que denominó "la alienación de los intelectuales" (discutiendo el concepto de "intelligentsia", el accionar de EE.UU., y la URSS en medio de la Guerra Fría). Esta obra fue central dentro de las producciones de este intelectual y se enmarcó en un momento de su carrera de gran participación en el debate intelectual.

Pasemos entonces a analizar en profundidad los contenidos de estas tres obras.

\section{Ejes de análisis}

Para realizar nuestro análisis comparativo, hemos construido cinco ejes de análisis, cuya conformación es sólo a los fines analíticos del presente trabajo. Hemos decidido organizar nuestro artículo, desarrollando estos ejes para cada intelectual, y luego problematizar las tensiones existentes entre ellos.

El primer eje, la construcción del discurso y la intertextualidad, se encuentra en íntima relación con el segundo, las reivindicaciones y las críticas de los tres intelectuales.

El tercer eje se basa en la definición y la función que debe desarrollar el intelectual.

En el cuarto, encontramos las propuestas o el plan de acción propuesto por cada intelectual.

Por último, el quinto eje es transversal, ya que se basa en algunos conflictos puntuales en el contexto de la Guerra Fría, que los intelectuales mencionan explícitamente y alrededor de los cuales se está debatiendo en este periodo. Nos centraremos en la guerra de Vietnam, el Mayo Francés, la política exterior de la URSS, posibles relaciones con la Segunda Guerra Mundial, las minorías raciales en los EE.UU., y la problemática en torno al expansionismo.

\section{Raymond Aron: una crítica a la intelectualidad francesa}

Comencemos por poner en relación nuestros dos primeros ejes de análisis, que se encuentran íntimamente conectados, en relación a la obra de Aron. El texto que aquí nos ocupa, El opio de los intelectuales (1955), presenta las características de un tratado que, a diferencia del escrito panfletario, no convoca sino que invita a la reflexión. Su interlocutor es más amplio que el 
campo intelectual francés, sin embargo en su texto encontramos constantes alusiones a los intelectuales de su época, dirigiéndose particularmente a JeanPaul Sartre en numerosas ocasiones. Aron encuentra una contradicción interna en la intelectualidad francesa: "Se considera a Francia como el paraíso de los intelectuales y a los intelectuales franceses como revolucionarios: tales son los hechos cuya conjunción parece paradójica." (1967: 216). Esta paradoja está dada por la relación que los intelectuales mantienen con la política; ésta lleva a que pocos sean los "intelectuales que viven de su pluma", quedando el resto mal pagos como simples profesores de los liceos o facultades francesas. Sin embargo, aquellos intelectuales que son reconocidos por la opinión pública, abogan por la eliminación de una sociedad que les permite "un nivel de vida honorable", a favor de una "Revolución mal definida", olvidándose de aquellos que no viven en tan buenas condiciones como ellos.

Podríamos deducir de estas frases, que la relación que ciertos intelectuales franceses (comunistas) mantienen con la política (régimen soviético) les evita cumplir con la función que dicen tener en la sociedad como guía de aquellos a quienes la República de Francia olvida (1967: 216, 217 y 223). Aron brinda a través de Sartre un ejemplo de este error de los intelectuales franceses: "El último artículo de Jean-Paul Sartre es un acontecimiento político o, por lo menos, es acogido como tal por un medio estrecho pero seguro de su importancia. Las ambiciones políticas de los novelistas de éxito chocan con las ambiciones literarias de los hombres de Estado. Éstos sueñan con escribir una novela y aquellos con llegar a ser ministros" (1967: 216).

Esta inversión de roles preocupa a Aron porque la principal consecuencia es la ceguera que suscita en los intelectuales. Si bien no podríamos decir que acuerda completamente con la política norteamericana, sí apoya su política exterior, defiende al país frente a las acusaciones comunistas, y muestra además cómo la Unión Soviética en el contexto de la Guerra Fría, también desarrolla tácticas de ofensiva, prepara armas nucleares, etc. (1967: 220). Sus críticas aquí también se refieren a los "revolucionarios soviéticos" que, mediante el partido bolchevique, se encargaron de producir lo que el devenir del capitalismo por sí solo no estaba provocando. Aron muestra permanentemente en su trabajo la centralidad del rol del partido para los comunistas soviéticos, su crítica a este partido, y su desacuerdo con el régimen stalinista, que a su entender no defiende los intereses que enuncia en su doctrina. Según Aron, "Armados de una doctrina que condenaba de antemano su empresa, los bolcheviques fueron los constructores de una sociedad industrial de un estilo antes desconocido [...] La clase obrera de Occidente, en el siglo XIX, se había erguido contra el patronato, no directamente contra el Estado [...] La ideología marxista ofreció una admirable justificación de las necesidades de una economía de Estado: los proletarios debían obediencia incondicional a su voluntad general, encarnada en el partido" (1967: 30). En el mismo sentido, Aron desconfía del régimen de las democracias populares, a las que no considera independientes de la URSS, como el régimen pretende simular, según él.

La crítica de Aron se materializa en los intelectuales franceses que, como Sartre, deciden convertirse en compañeros de ruta del PC francés, reduciendo su rol bajo la ceguera que el partido les provoca, posicionándose en contra del régimen del EE.UU. por su desconocimiento de la sociedad norteamericana 
(1967: 258-259). La temática de las minorías raciales en EE.UU., particularmente las comunidades negras, es uno de los focos de discusión con los intelectuales comunistas. Aron argumenta fuertemente aquí en defensa de Ios EE.UU., y marca el desconocimiento de la problemática de quienes critican al capitalismo, afirmando que la condición de esta comunidad ha mejorado, y no ha optado por el comunismo o la revolución, ya que su reivindicación central es ser ciudadanos norteamericanos. En la misma línea, Aron encuentra un recelo por parte de los intelectuales europeos, dado que las promesas que la izquierda pretendía, las ha logrado el capitalismo norteamericano, mejorando ampliamente el nivel de vida de la población.

Para Aron, "la nostalgia" del universalismo que abandona el intelectual francés al sumarse a la causa comunista, crea la contradicción en el seno mismo de éste, ya que Francia pertenece al "mundo no comunista" (1967: 303). Precisamente el arte de los intelectuales franceses es para Aron el desprenderse de los problemas nacionales en nombre de ese universalismo, de pensar por la humanidad toda, errando el camino: "En lugar de plantear la pregunta razonable: ¿Qué hacer cuando los obreros votan en gran número por el partido comunista, en un país que está, geográfica y espiritualmente, en el interior del campo occidental?, meditan acerca de la vocación revolucionaria de un proletariado soñado por Marx; plantean la equivalencia mítica del proletariado y del partido comunista." (1967: 242).

La mayor crítica que encontramos en Aron se basa en la "religión" en que ha devenido el comunismo, construyendo una "doctrina" que envuelve a los intelectuales, delimitándoles los valores y jerarquías que deben perseguir, cual "espíritu de las cruzadas" (1967: 258-259). Aron recuerda que Marx definía a la religión como "el opio de los pueblos"; ahora la religión del marxismo se convertía en "el opio de los intelectuales". De allí el título de su obra. Los intelectuales occidentales, adhieren así a la doctrina marxista-leninista por la fuerza que ésta reviste como "religión secular", y, fanatizados por ella, arrastran al proletariado bajo sus preceptos: "La religión secular guarda el prestigio y la fuerza del profetismo, suscita un pequeño número de fanáticos y éstos, a su vez, movilizan y encuadran a las masas, no tanto seducidas por la visión del porvenir como rebeladas contra las desdichas del presente." (1967: 306).

Las críticas más profundas del autor hacia el marxismo como doctrina, se refieren al rol que ésta le otorga al proletariado como la clase que lleva en sí la clave para la revolución. Allí, para Aron, el joven Marx se equivoca, y agrega que todas las revoluciones europeas han sido burguesas, e ideadas por los intelectuales burgueses (1967: 298-299).

En relación a nuestro tercer eje de análisis, que hace a la función que debe desarrollar el intelectual, podemos decir que la definición del intelectual que enuncia Aron (en la tercera parte de su libro), está dada por su concepto de "la intelligentsia" y de "intelectual", a la vez que observamos que la función que éste debe desarrollar está presente en el texto siempre por la negativa; es decir, su definición y función del intelectual está definida por los errores que éstos no deben cometer. En este sentido, los intelectuales versarían sobre distintas "especies" -escribas, expertos, letrados y profesores- y la definición de los "profesionales de la inteligencia" varía según el significado otorgado en la 
URSS (expertos y técnicos calificados) o en Occidente (escritores, sabios, artistas, profesores).

Aquí nos encontramos con una dificultad en el texto, que obstaculiza individualizar ambas categorías; aparentemente el autor quiere mostrar que ambas categorías se van desdibujando al ingresar a la esfera política y en la administración del Estado, convirtiéndose en "intelectuales-funcionarios". Sin embargo, este es un punto del autor que no logramos aclarar en la obra. Quizás esta situación se deba a que permanentemente se hace presente su crítica al accionar de los intelectuales, y ello oscurezca una definición más nítida.

En cuanto al cuarto eje de análisis, el plan de acción propuesto, en esta obra está menos presente o explícita la propuesta del autor sobre el camino a seguir. Nuevamente lo que observamos es que por la negativa expresa, sino una propuesta, su deseo. Éste estaría relacionado con terminar con el "fanatismo" en el que han caído los intelectuales franceses, así como con su alejamiento de la esfera política, que niega por sí misma la misión del intelectual.

Concluye la obra con la siguiente frase, que podría expresar esta propuesta: "[...] Quizá el intelectual llegue a desinteresarse de la política el día en que descubra sus límites. Aceptemos alegremente esta promesa incierta [...] debe enseñarse a dudar de los modelos y de las utopías, a recusar a los profetas de salvación, a los anunciadores de catástrofes. Hagamos votos por el advenimiento de los escépticos, si ellos han de extinguir el fanatismo." (1967: 310).

\section{Herbert Marcuse: un acercamiento al final de la utopía}

Trasladándonos hacia Herbert Marcuse, El final de la utopía recopila un conjunto de conferencias que éste brinda en 1967 en Berlín, por lo que el primer eje, la construcción del discurso, se relaciona con un público propio del ámbito universitario. Quizás aquí lo interesante es que el interlocutor, al estar presente en las conferencias y sus debates, puede preguntar y repreguntar a Marcuse, provocando como resultado que ahonde más en su perspectiva.

Desde nuestro segundo eje, críticas y reivindicaciones, en Marcuse se expresa claramente que "el final de la utopía" ha llegado, ya que la "imposibilidad" que define a la "utopía" (como "concepto histórico") queda eliminada por las condiciones que se habían generado de una "clase revolucionaria", puesto que "En efecto, todas las fuerzas materiales e intelectuales necesarias para la realización de una sociedad libre están presentes" (1986: 8) (distinguiéndose de la sociedades existentes capitalistas). Ese final de la utopía estaría dado por la ruptura de las "necesidades en la sociedad represiva", mediante la puesta en marcha de las "fuerzas materiales e intelectuales" necesarias para la transformación; aún la "transformación técnica" (puesta al servicio de las nuevas necesidades) no podría generar la imposibilidad de dicha transformación.

A lo largo de la primera conferencia, Marcuse responde acerca de las críticas sobre su concepto del "final de la utopía". No se trataría para él de buscar una "sociedad sin conflictos" (esto sí sería algo verdaderamente utópico), ni de una 
sociedad donde no exista el trabajo, sino de incluir a éste en el "reino de la libertad" mediante la concientización de las necesidades (1986: 34): "No se trata de una sociedad sin conflictos... ésta sería una idea utópica. La idea de una sociedad en la cual siguen existiendo obviamente conflictos, pero esos conflictos se puedan resolver sin opresión, sin crueldad, no es en mi opinión una idea utópica. Por lo que hace al concepto de democracia." (1986: 43). Asume que será necesaria "una intervención" para que esto suceda, y allí anclará su plan de acción para los jóvenes e intelectuales.

Continuando con las críticas del autor, el debate en torno a la Guerra de Vietnam recorre gran parte de la obra, develando en realidad el enfrentamiento entre los dos bloques inmersos en la Guerra Fría: "En Vietnam se trata de dejar caer bajo control comunista una de las zonas estratégicas y económicamente más importante del mundo. Se trata de una lucha decisiva contra todos los intentos de liberación nacional en todas las partes del mundo, lucha decisiva en el sentido de que un triunfo de la lucha de liberación vietnamita podría dar la señal de una activación de esas luchas de liberación en otros continentes [...]" (1986: 59). Esta misma guerra dejó entrever los objetivos de expansión de EE.UU., lo que produjo el reforzamiento de "la Oposición" de los estudiantes norteamericanos. Sin embargo, reconoce que la Oposición es "vergonzosamente pequeña y débil en comparación con las cosas siniestras que ocurren en Vietnam" (1986: 167).

También respecto de la construcción de esta Oposición, en las conferencias se debate sobre el rol de las "luchas de liberación del Tercer Mundo". Marcuse toma posición también sobre esta temática, y manifiesta a los estudiantes la importancia que estos movimientos poseen para la caída del capitalismo. Sin embargo, considera que el colonialismo debe quebrarse conjuntamente en las Metrópolis, para que pueda darse la caída del sistema.

Dentro de sus críticas, es importante destacar en el contexto alemán (y relacionado con su participación previa a la República de Weimar), que encontramos una disidencia importante con el partido socialdemócrata alemán, quien a su entender "[...] ha trabajado en alianza con fuerzas reaccionarias, destructivas y represivas." (1986: 81). Además no observa posibilidad de un cambio radical que revolucione el interior del partido. No es aquí donde Marcuse encuentra las fuerzas para la transformación del sistema.

Finalmente Marcuse se posiciona frente al régimen soviético. Observa la "colaboración" de la URSS y EE.UU., y manifiesta que es crítico en cuanto a lo que ocurre en los países socialistas; debate con sus colegas en las conferencias sobre el cambio de rumbo que tomó la revolución rusa con el stalinismo, y manifiesta que su idea de democracia no está representada en los países socialistas.

Introduzcamos nuestro tercer eje, el rol del intelectual, relacionándolo con la propuesta o plan de acción que Marcuse propone. Dado que ha llegado el final de la utopía y se acercan las posibilidades para la trasformación, "Los intersticios están abiertos en la sociedad existente, y el aprovechamiento constituye una de las tareas más importantes" (1986: 28). Las "grietas" del sistema social existen, pero es necesario sacarlas a la luz; fundamentalmente es necesario generar la conciencia de que la "transformación es objetivamente 
necesaria" y que los mecanismos que obstruyen a las clases que desean esa transformación, sean desmantelados (1986: 67-68).

Estas grietas del sistema deben ser "agrandadas" por el intelectual, en su rol de concientizar a los trabajadores sobre la existencia de las necesidades para que la transformación sea posible, y no ya utópica (1986: 134). Desde la "teoría crítica" (marxismo) a la que Marcuse dice pertenecer, intenta pensar las características de la "sociedad libre"; en este sentido, las conferencias recuperan las experiencias de este intelectual en EE.UU., en el contexto de la Guerra de Vietnam y la sociedad de consumo que mencionamos en nuestro apartado de contextualización. Esta sociedad de confort y de "trabajo alienado" obstaculiza la toma de conciencia del "factor subjetivo" que el intelectual debe traer a escena para lograr la trasformación.

Una de las temáticas de la conferencia se basa en el lugar que ocupa el intelectual como portador de la "luz" que debe ser llevada a los trabajadores; Marcuse responde a esta temática afirmando que no se trata de fomentar intelectuales de la ilustración: aquí al igual que Sartre, el intelectual puede ver esas contradicciones que él mismo porta, y por eso sería capaz de descubrir y mostrar a los trabajadores las condiciones que los oprimen y les ocultan la posibilidad de trasformación, bajo el velo de la utopía. De la misma forma que para Sartre, una vez ocurrido el Mayo Francés, son los jóvenes los que pueden llevar a cabo la función del verdadero intelectual apoyando a los "más desfavorecidos". Según Marcuse, "[...] no podemos suponer que el éxito de la oposición estudiantil lleve directamente la situación a una etapa en la que podamos plantearnos siquiera la cuestión relativa a la construcción de una sociedad libre. Si la oposición estudiantil permanece aislada, si no logra salirse de su propio círculo y movilizar capas realmente susceptibles [...] de desempeñar en la revolución un papel decisivo, entonces la oposición estudiantil no puede representar más que un papel secundario" (1986: 63). Observemos la importancia que Marcuse le otorga al hecho del aislamiento del intelectual, que imposibilitaría el acercamiento a la sociedad libre.

Aquí es importante remarcar el rol central que Marcuse otorga a los estudiantes, y su preocupación por que los estudiantes que terminan la Universidad sigan formando parte de la Oposición. En relación con ello, observa una necesidad imperiosa de luchar por la libertad académica que incluya a los estudiantes en las decisiones. Ésta es una de las posturas que le brindaron popularidad entre los estudiantes alemanes.

Concluyamos remarcando que si bien para Marcuse la oposición intelectual es central, no considera que sea en sí misma una "fuerza revolucionaria", ya que observa que se encuentra en un momento de "preparación necesaria" para unirse a otros movimientos de oposición que logren generar la crisis del sistema capitalista. De allí que si continúa aislada junto con los estudiantes, no podrá superar ese momento de preparación.

\section{Jean-Paul Sartre: una interpelación a nuestro rol como intelectuales}

Retomando nuestro primer eje pero ahora a partir del texto de Jean-Paul Sartre, Alrededor del 68. Situación ocho, la parte final de la obra se dedica particularmente a los intelectuales, recopilando varias conferencias y una 
entrevista realizadas entre el 65' y el 70'. Aquí, Sartre ya se encuentra en los últimos años de su vida y es por esta razón que la construcción del discurso recupera su experiencia y su propia trayectoria (como su paso por el PC), posicionándose en algunos aspectos de modo diferente al panorama que nos describía Aron en los 50'.

Es importante destacar desde este eje de intertextualidad, que en la definición de "filósofos", en contraposición a los intelectuales orgánicos, Sartre recupera explícitamente a Gramsci. También rescata a Nizan. y su concepto de "perros guardianes", homologándolo a su propio concepto de "falsos intelectuales", quienes socavan las bases de los intelectuales defendiendo la ideología de las clases dominantes: como los "reformistas" que presentan "argumentos moderados", frente a quienes los "verdaderos intelectuales" deben defender sus propios argumentos, constituyéndose en "revolucionarios", rechazando la propuesta engañosa de mantener el statu quo que es lo que ofrecen finalmente los reformistas, como podríamos inferir en el caso del reformismo de Aron (1973a).

Introduciéndonos en el eje de la definición y la función que debe desarrollar el intelectual, Sartre en su primer conferencia define al intelectual como un "producto histórico", aquel que "se mete en lo que no le concierne", y como hombre que adquiere "notoriedad" entre el resto de la gente, es portador del derecho de desarrollar su dogma y criticar a esta sociedad (1973a).

Esta concepción común del intelectual, requiere para Sartre realizar una diferencia que esclarezca la función que posee como tal. Por un lado existirían "los técnicos": "[...] intelectual en potencia puesto que es definido por una contradicción que no es otra que el combate permanente, en él, de su técnica universalista y de la ideología dominante" (1973a: 301). Al ser producidos por la "clase dominante", una "contradicción los desagarra": por un lado, son "asalariados" y funcionarios de la superestructura, y por el otro son "especialistas" de "lo universal" y portan un "particularismo" que "no pueden impugnar o se impugnarían a ellos mismos". En este sentido, niegan que exista una "ciencia burguesa", sabiendo que su existencia no solo es real, sino que son ellos quienes la desarrollan. Por otro lado, estaría el intelectual, que sólo puede aparecer si estas contradicciones provenientes de la clase dominante son superadas, peligro que "el poder" conoce, por lo que considera a los técnicos como "eminentemente sospechosos", ya que "todo técnico del saber es intelectual en potencia".

Sin embargo, el intelectual, "producto monstruoso" de la sociedad que lo rechaza y que no posee "mandato de nadie" (ni de la "clases dominantes", ni de la "clases medias", ni de las "clases desfavorecidas"), ostenta un papel: "[...] el intelectual, definido como toma de conciencia de su contradicción constitutiva, puede ayudar a la constitución de la toma de conciencia proletaria" (1973a: 318), comprendiendo la "singularidad histórica" del proletariado y la necesidad de la "universalización de su particularidad" para que ellos logren encarnar la revolución. Así se transformarían para Sartre en "guardianes de los fines históricos que las masas persiguen".

Sartre continúa este argumento planteando lo que a su entender sería la resolución de las contradicciones del intelectual: "No es diciendo: 'No soy un pequeño burgués, me muevo libremente en lo universal' que el intelectual 
puede unirse a los trabajadores, sino muy al contrario, pensando: soy un pequeño burgués, si para intentar resolver mi contradicción me he alineado junto a las clases obreras y campesinas, no por ello he dejado de ser un pequeño burgués: simplemente, criticándome y radicalizándome sin cesar, pude rechazar uno a uno -sin que eso interese a nadie más que a mí- mis condicionamientos pequeño-burgueses." (1973a: 319). Y concluye diciéndonos: "El oficio del intelectual es vivir su contradicción para todos y superarla para todos por el radicalismo (es decir por la aplicación de técnicas de verdad a las ilusiones y las mentitas)." (1973a: 325).

En íntima relación con los interlocutores que mencionábamos en el primer eje, nos encontramos con el cuarto eje de análisis. Sartre plantea desde su propia trayectoria, una propuesta que llevaría al intelectual a cumplir con su rol a través del acercamiento a los "más desfavorecidos", ya que su existencia contradice la "ideología creada desde arriba", desenmascarando la sociedad de clases.

En esta tarea, el "intelectual verdadero" desarrolla distintas estrategias para sortear los obstáculos que pueden impedir que cumpla su rol: "[...] es necesario que haya en los partidos o en las organizaciones populares, intelectuales asociados al poder político, lo que representa el máximo de disciplina y el mínimo de críticas posibles; y es necesario, también, que haya intelectuales fuera de los partidos, individualmente unidos pero desde afuera, lo que representa el mínimo de disciplina y el máximo de críticas posibles" (1973a: 321).

En este mismo sentido, Sartre manifiesta que el "oportunismo del aparato popular", al igual que el de la clase dominante, pueden intentar acallar las voces de los verdaderos intelectuales (mediante las purgas), pero frente a este intento del "poder", el rol del intelectual no debe interrumpirse, pues seguirá siendo el "defensor de las clases populares" en tanto pueda seguir hablando y escribiendo (1973a: 324). Finalmente, ya en los 70', ocurrido el Mayo Francés, Sartre observa que ese rol lo pueden cumplir los "aprendices de intelectuales" ("tipos salidos de mayo", como los llama) interviniendo junto a los "movimientos de masas" (1973b: 348-352).

El Mayo Francés conforma para Sartre un quiebre importante en la manera de pensar la intelectualidad, ya que es en medio de ese proceso que "los intelectuales clásicos" son cuestionados e interpelados por los estudiantes que entendieron que no quería convertirse en ellos, y cumplir su rol a favor de las clases dominantes. Sin embargo, asume que aún no se ha producido una ruptura de la figura del intelectual clásico, pero sí se empieza a plantear a raíz del Mayo, qué lugar desean ocupar en la sociedad los futuros intelectuales, los graduados de las universidades francesas. Por eso considera a los "tipos salidos de mayo" los actores que pueden cambiar el sentido de la intelectualidad, a través de lo que denomina "células mixtas" que fusionen obreros e intelectuales, y abandonar de una vez las células separadas, y unificar así a los dos movimientos.

Es interesante observar aquí, cómo Sartre recupera su experiencia de prisionero durante la Segunda Guerra Mundial, donde convivía con obreros y campesinos prisioneros. Coloca como ejemplo este hecho, donde pudo interactuar con los trabajadores porque compartieron una situación de vida 
juntos. Si en lugar de ello, les hubiera ido a hablar a sus fábricas desde su lenguaje abstracto de intelectual, manifiesta, seguramente no lo hubieran escuchado. Por esta razón plantea esta necesidad de unificar el movimiento obrero e intelectual.

Sartre realiza una dura crítica al accionar del PCF (Partido Comunista Francés) durante el Mayo Francés, ya que debido a su marxismo ortodoxo, frenó el movimiento de los estudiantes, impidiendo la relación con el movimiento obrero, en lugar de apoyarlo. Para Sartre, el PCF no tuvo una actitud revolucionaria, ni siquiera reformista, frente a los acontecimientos del mayo. En esta misma línea, critica la perspectiva de Marcuse, quien a su entender peca de un "pesimismo revolucionario", al ver sólo en los obreros, la posibilidad de un movimiento revolucionario; para Sartre, lo ocurrido en el Mayo demostró que hay otros grupos que pueden desencadenar movimientos espontáneos, y que pueden ser apoyados por los obreros al mismo tiempo. Además, observa una mutua influencia entre los estudiantes alemanes y franceses, y ve allí la posibilidad de que un movimiento similar ocurra en Alemania. ${ }^{3}$

En relación con aquel rol del "intelectual clásico", Sartre critica duramente a Aron como intelectual y como profesor. Estas críticas, se encuentran en sus declaraciones en Le Nouvel Observateur, que recopila en su libro bajo el título de Las bastillas de Raymond Aron. Según Sartre, Aron considera que los estudiantes no saben nada aún, y por esta razón no deben discutir en las clases, ni intervenir en las decisiones de la universidad (de allí, que fue un ferviente opositor del Mayo Francés, y organizó la resistencia al movimiento). Por su parte, Sartre está convencido que el método de enseñanza-aprendizaje debe cambiar, y permitir mayor acceso a la educación universitaria.

Continuando con la comparación con Aron, también podríamos observar cómo Sartre, al construir una propuesta de intelectuales por fuera y por dentro de los partidos, limitaría las críticas de Aron en cuanto a la ceguera que ocasionaba el PC a los intelectuales que se sumaban a la causa de la revolución. En este escrito, Sartre podría estar de acuerdo con las denuncias que Aron refería a la URSS, y su intento de manejar a los intelectuales tanto internos como externos al régimen (las purgas a la oposición de Stalin, servirían de ejemplo, ya que por la fecha de este texto, Sartre ya había viajado a la URSS y se había desencantado del régimen).

En torno a la temática sobre la política exterior de EE.UU., también podríamos marcar diferencias entre Aron y Sartre. Para ello, trabajaremos aquí sobre la primera parte de la obra de Sartre que ronda alrededor de la temática de la guerra de Vietnam. En esta parte, Sartre recopila distintas intervenciones en Le Nouvel Observateur (en 1965 y 1966), en los apartados llamados "Ya no hay diálogo posible" y "El crimen"; también publica un artículo en Les Temps Modernes (de 1967), que titula "El genocidio".

\footnotetext{
${ }^{3}$ Podemos observar como en esta obra, Sartre revisa su tesis expuesta en Problemas del Marxismo I (1962), donde defendía aún el rol del PCF. Luego del Mayo Francés, y durante todo el gobierno de De Gaulle, este intelectual se configura en un ferviente crítico del accionar del PCF. "Masa, espontaneidad, partido" (dentro del Alrededor del 68), expresa las diferencias entre su defensa al PCF y la URSS. en la década del 50' y sus opiniones registradas luego del Mayo francés.
} 
Si bien la obra de Aron que analizamos es anterior a la guerra, este intelectual apoya la política exterior norteamericana. Sartre, contrario siempre a esta política, y ya como integrante del "Tribunal Russell" (iniciado en 1967), considera la guerra un reflejo de la política exterior norteamericana. El tribunal termina concluyendo que, dentro de la legislación internacional, en la guerra de Vietnam se cometieron crímenes de guerra, teniendo como antecedente los juicios de Nüremberg de 1945. Sartre considera que la acción de EE.UU. en Vietnam es un genocidio, un exterminio masivo, y termina homologando esta acción con el racismo del régimen nazi: "[...] la verdad de la guerra de Vietnam: ella se une a las declaraciones de Hitler. Éste mataba a los judíos porque eran judíos. Las fuerzas armadas de los Estados Unidos torturan y matan hombres, mujeres y niños del Vietnam porque son vietnamitas. Así, cualesquiera que sean las mentiras y las preocupaciones verbales del gobierno, el espíritu de genocidio está en la cabeza de los soldados." (1973c: 93) (El subrayado es original).

\section{Palabras finales}

A modo de síntesis, quisiéramos exponer algunas comparaciones que surgen de lo analizado hasta aquí. En primer lugar, el intelectual que logre enfrentar las contradicciones que porta en su propio ser, y fundamentalmente se acerque a las clases oprimidas concientizándolas de las características que tienen y de la posibilidad del cambio, será el "verdadero intelectual" para Sartre y el que demuestre el final de la utopía y el comienzo de la transformación para Marcuse. Para Aron, en cambio, desde su postura reformista, el ideal universal propio del intelectual francés no es superable porque forma parte de su esencia, y al enceguecerse con modelos externos a Francia (como el soviético), se llega a extremos como el "fanatismo" o la "religión", eliminando así las libertades del intelectual propiamente dicho.

Esa contradicción inherente al intelectual, que Aron ve como un inconveniente, Sartre y Marcuse la encuentran como la clave, una vez superada, para ayudar a concientizar a los trabajadores de sus propias contradicciones. Ambos, también coinciden en el rol central de los estudiantes en la transformación de la sociedad capitalista.

En segundo lugar, los tres intelectuales son críticos del régimen soviético aunque, como hemos podido observar, de distinta manera. Marcuse y Sartre, vislumbran en la URSS rasgos que no son propiamente socialistas, no al menos en el sentido que ellos entienden lo que debería ser una democracia socialista. Aron es muy crítico del régimen soviético, particularmente de las democracias populares, donde ve un claro objetivo de expansión. Los tres también observan en los partidos socialistas errores que corresponden a su doctrina y a un exceso de teoría por sobre la práctica (cada uno realiza esta crítica con una intencionalidad claramente diferente).

En Sartre y Marcuse, observamos una crítica que corresponde al error del accionar en momentos críticos de la sociedad, donde los partidos socialistas y comunistas en post de su doctrina, abandonaron a los trabajadores. Por su parte, Aron manifiesta el error de la doctrina, pero también acusa al régimen de ocultar sus verdaderos objetivos expansionistas y sus intenciones sobre los PC de los países occidentales. Los intelectuales serían aquí culpables de caer en 
el fanatismo y el profetismo de la doctrina marxista-leninista que este régimen, y el partido bolchevique particularmente, manifiestan.

En tercer lugar, en lo que se refiere a la guerra de Vietnam, Sartre y Marcuse, mantienen una postura similar en cuanto a la intención de expansión de la política exterior de los EE.UU. en el contexto de la Guerra Fría. También ambos ven rasgos de fascismo en esta política y en el maltrato al pueblo vietnamita, como una cristalización del racismo del régimen nazi. Aron se posiciona claramente a favor de la política exterior de los EE.UU. (previo a la guerra de Vietnam), y critica el ocultamiento del expansionismo de la URSS.

Como hemos intentado mostrar a lo largo del presente trabajo, los tres intelectuales analizados presentan una perspectiva crítica del rol del intelectual en el contexto de la Guerra Fría, siendo actores que juegan un papel central en el debate intelectual de la época, dentro del cual se pone en juego permanentemente sus propias experiencias, signadas por la Segunda Guerra Mundial y la posterior división del mundo en dos bloques enfrentados.

Creemos haber expresado cómo esta problemática atraviesa las obras analizadas, y cómo los intelectuales intervienen activamente desde ellas.

Finalmente, y a título personal, creo que el debate descripto en estas páginas podría aportar al esclarecimiento del rol del intelectual en la actualidad, cuestionando nuestras acciones e interrogándonos sobre el lugar que deseamos ocupar y la "misión" que debemos/queremos cumplir dentro de nuestra sociedad.

\section{Bibliografía}

(1967) ARON, Raymond, El opio de los intelectuales, Ediciones Siglo Veinte, Buenos Aires.

(1973a [1972]) SARTRE, Jean-Paul, "Defensa de los intelectuales". En Alrededor del 68. Situación VIII, Losada, Buenos Aires.

(1973b [1972]) SARTRE, Jean-Paul, "El amigo del pueblo". En Alrededor del 68. Situación VIII, Losada, Buenos Aires.

(1973c [1972]) SARTRE, Jean-Paul, "El genocidio". En Alrededor del 68. Situación VIII, Losada, Buenos Aires.

(1986) MARCUSE, Herbert, El final de la utopía, Planeta-Agostini, Barcelona.

(1995) HOBSBAWM, Eric J., Historia del siglo XX, Crítica, Barcelona.

(2005) ALTAMIRANO, Carlos, "Ideas para un programa de historia intelectual". En Para un programa de historia intelectual y otros ensayos, Siglo XXI, Buenos Aires.

(2006) RICOUER, Paul, “¿Qué es un texto?”. En Del texto a la acción. Ensayos de hermenéutica II, Fondo de Cultura Económica, Buenos Aires. 